\title{
Effect of aspirin on explanted gastric mucosa
}

\author{
FREDERICK O. STEPHENS, GERALD W. MILTON, AND JOHN LOEWENTHAL
}

From the Department of Surgery, The University of Sydney, Australia

EDITORIAL SYNOPSIS Direct application of powdered aspirin inhibited histamine-stimulated acid secretion and this was followed by superficial inflammation and destruction of the mucosa.

Naturally occurring salicylates existing in a great variety of plants have been used as medical remedies over the centuries by scattered tribes and civilizations. Since acetylsalicylic acid (aspirin) was introduced in 1899, its strong analgesic action has resulted in its becoming the most widely used medication today.

Although ingestion of aspirin has long been known to be associated with gastro-intestinal disturbances, both functional (nausea, vomiting, and epigastric distress) and pathological (ulceration and haemorrhage), the mode of action of these disturbances is not clear. There is evidence to suggest that factors other than gastric irritation play a part in the production of the nausea (Caravati and Cosgrove, 1946), and Wood (1963) has postulated an inhibitory effect on digestive ferments as being responsible.

The present experiments were designed to make direct observations on the effect of aspirin applied locally upon the acid secretory function of gastric mucosa and to relate this with histological appearances.

\section{MATERIALS AND METHODS}

Sixteen adult dogs were used. Under intravenous Nembutal anaesthesia a section of full-thickness gastric wall with an intact blood supply was brought through a stab incision in the animal's abdominal wall and sutured over an equivalent area from which the skin had previously been excised (Figs. 1 and 2). Immediately after the formation of the explant the animal was given an intramuscular injection of histamine acid phosphate $(0.5 \mathrm{mg} . / \mathrm{kg}$. body weight $)$ and the $p \mathrm{H}$ response determined by observing the colour change in universal indicator paper which was laid over the explant. In eight animals the anterior half of the explanted mucosa was covered with $0.5 \mathrm{~g}$. of powdered aspirin. After one hour the aspirin was washed off with water and the response of the explant to a further injection of histamine was again determined. Twenty-four hours later the histamine test was repeated.

In two further experiments, after application of the aspirin, the injection of histamine was repeated every
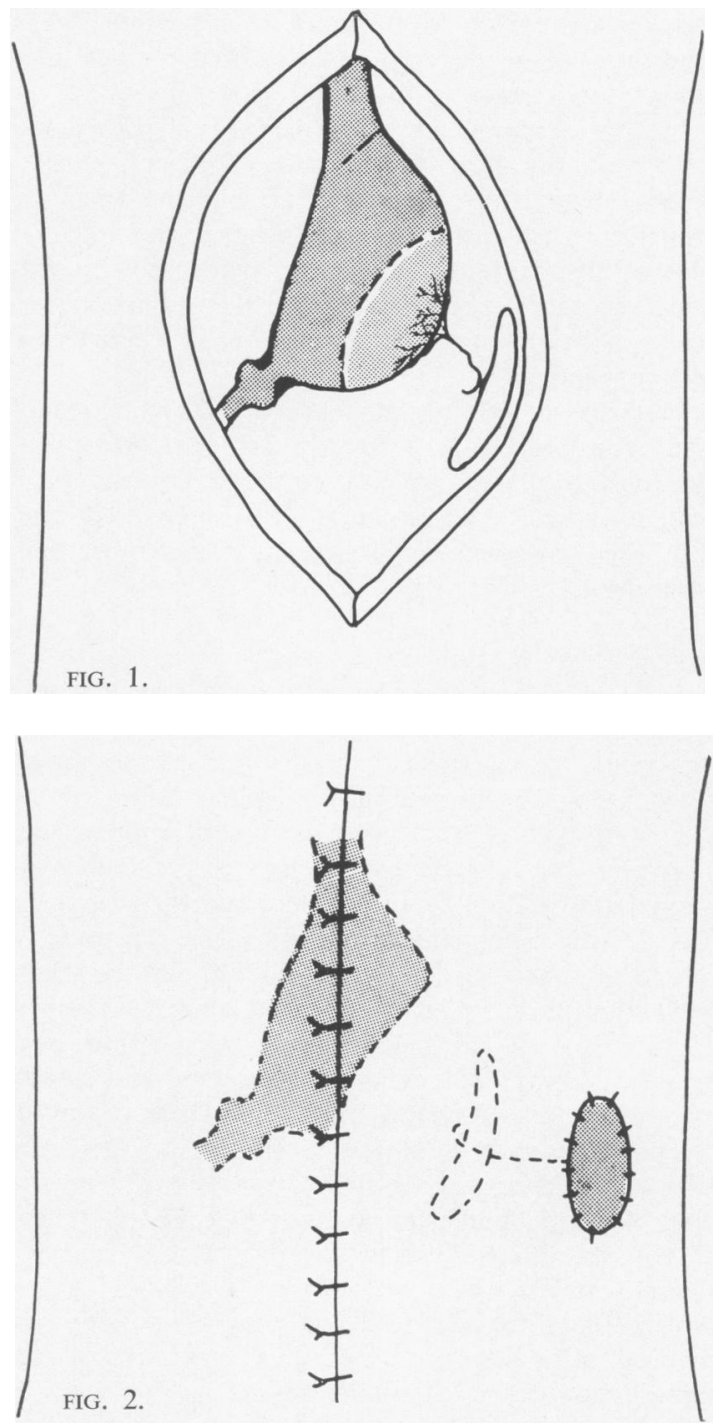

FIGS. 1 and 2. Diagrams illustrating the stages in making the gastric wall explant. 
two hours for 24 hours and the $p \mathrm{H}$ response determined after each injection. These animals were anaesthetized throughout this period by repeated intravenous Nembutal. Biopsy specimens from the explants were taken at various stages in all experiments.

\section{RESULTS}

The fluid on the surface of each of the 16 freshly made, unstimulated explants was slightly alkaline

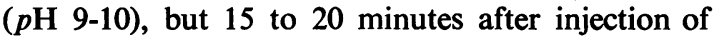
histamine the reaction became strongly acid $(p \mathrm{H} \mathrm{1-2)}$. In the control animals the explant continued to show a strongly acid response to histamine for a minimum of three days post-operatively, as previously reported by Milton and Finckh (1960).

In those explants partly covered with powdered aspirin for one hour there was no further secretion of acid from the covered area from the time the aspirin was removed, but at that stage the adjacent part of the explant not covered with aspirin continued to secrete acid. However, this adjacent area also consistently failed to secrete acid when tested 24 hours later.

In the two animals given repeated injections of histamine two hourly, after the removal of aspirin, although the area which had been covered with aspirin failed to secrete acid, the uncovered area continued to secrete acid when stimulated more than 24 hours later.

APPEARANCE OF THE EXPLANTS The application of aspirin caused visible changes in the macroscopic appearance of the explants. To the naked eye there was evidence of oedema and small haemorrhagic petechiae on the surface of the explants immediately after removal of the aspirin. These appearances increased over the next 48 hours. Microscopically, immediately after the removal of the aspirin, there was a little intercellular oedema (Figs. 3 and 4). Over the following 24 hours subepithelial red cells and inflammatory cells appeared, there was progressive loss of epithelial surface cells with a continuing increase of oedematous spaces, and finally a complete loss of surface epithelium (Figs. 5 and 6). Deeper the gastric glands appeared to be little affected by this superficial inflammation during the first 24 hours, but after 48 hours the full thickness of gastric mucosa was involved (Figs. 7 and 8). There was no obvious evidence of absorption of aspirin from the surface. The area of explant not covered with aspirin showed a less severe and slower progression of similar inflammatory changes (Figs. 9 and 10). When the histamine was repeated two hourly, inflammatory changes did not spread to the adjacent mucosa.

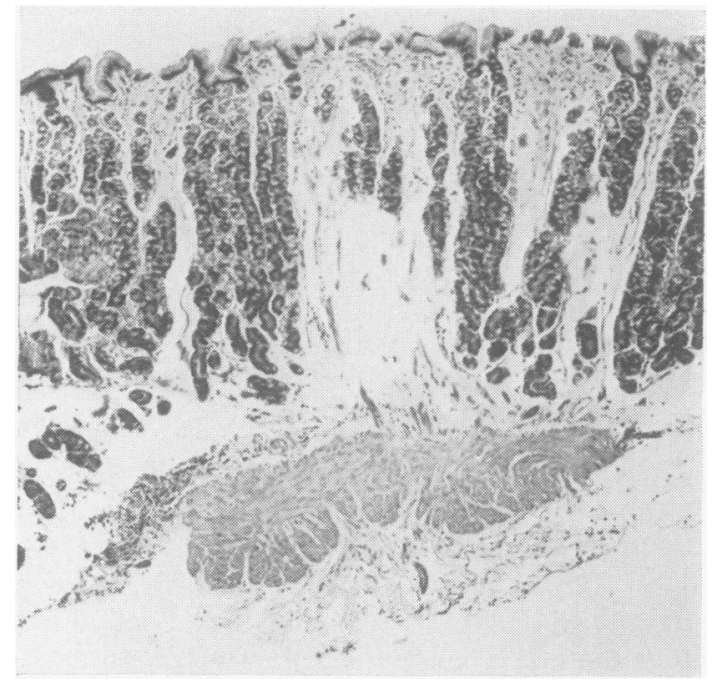

FIG. 3. Explanted gastric mucosa immediately after removal of aspirin. There is a little disruption of surface epithelium and some intercellular oedema. Haematoxylin and eosin $\times 50$.

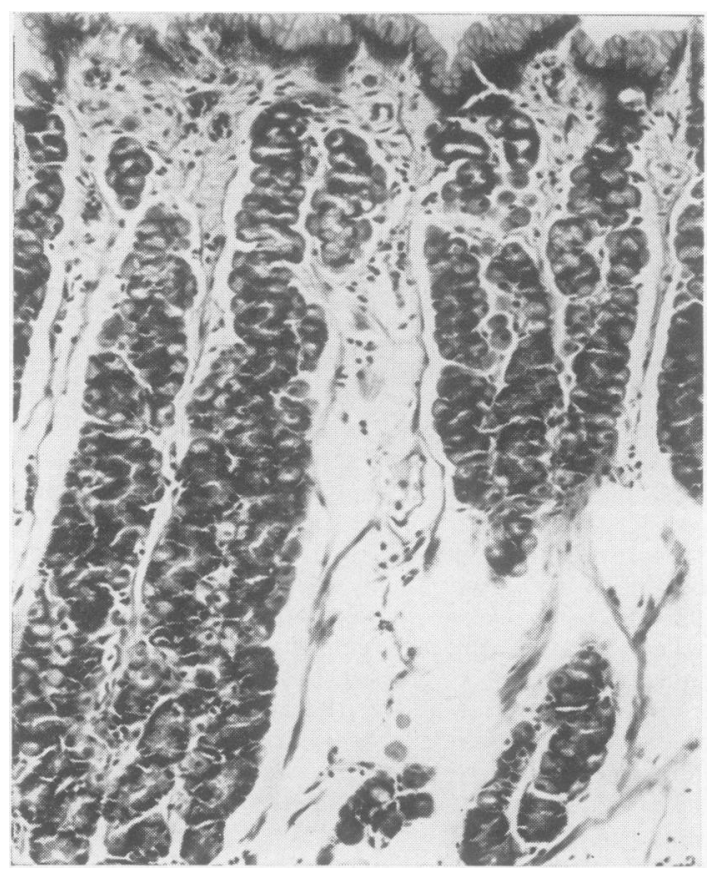

FIG. 4. The same as Figure 4. Haematoxylin and eosin $\times 130$. 


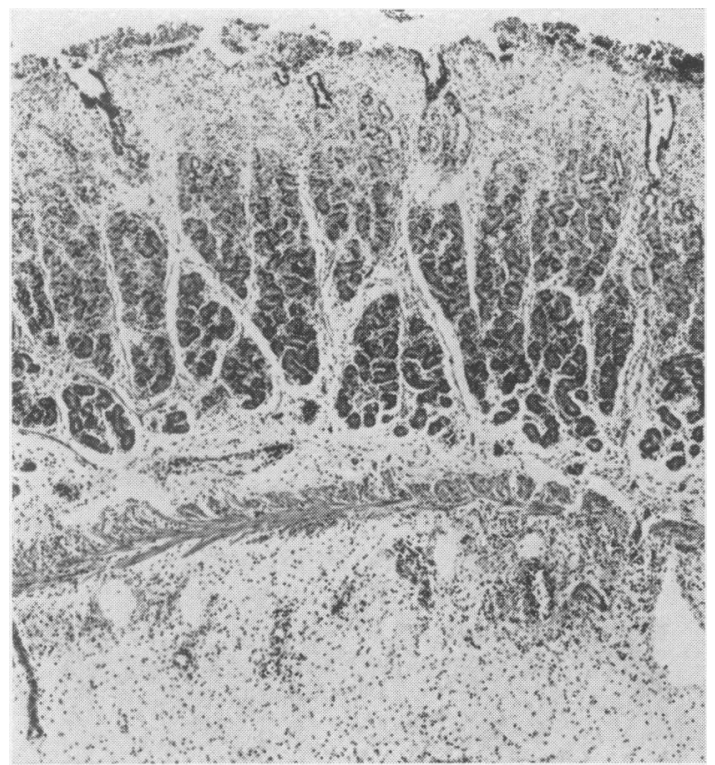

FIG. 5. Explanted gastric mucosa 24 hours after removal of aspirin. There is loss of surface epithelium with considerable inflammatory reaction. Haematoxylin and eosin $\times 50$.

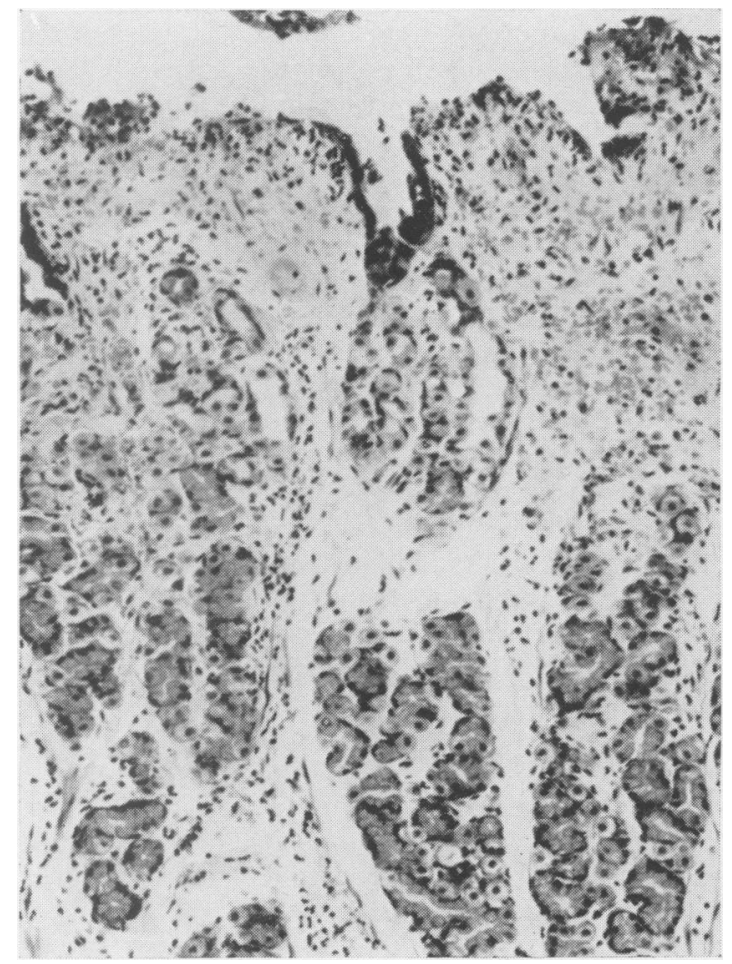

FIG. 6. The same as in Figure 5. Haematoxylin and eosin $\times 130$.

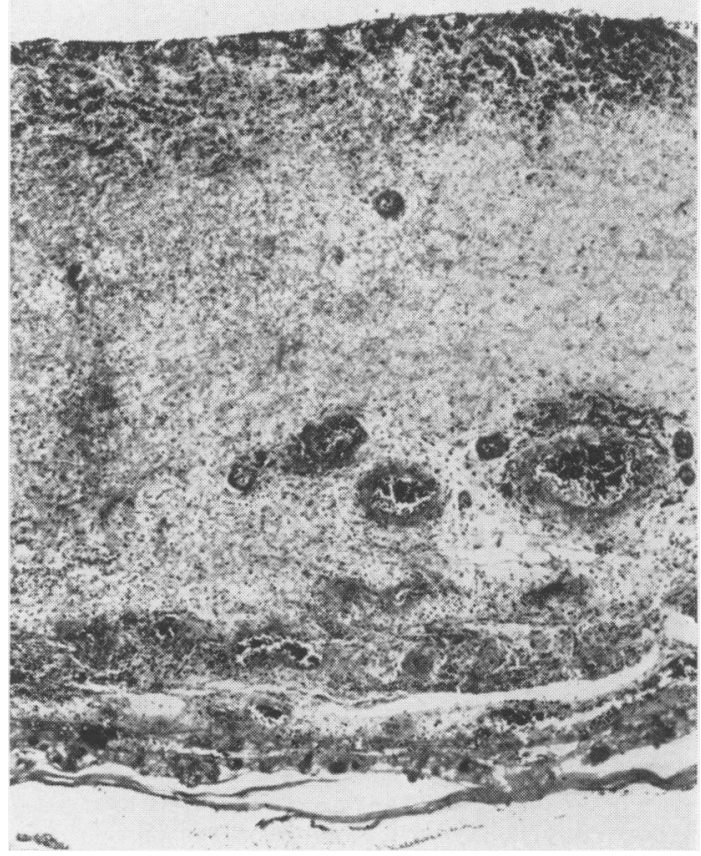

FIG. 7. Explanted gastric mucosa 48 hours after removal of aspirin. The mucosa has been completely replaced by granulation tissue. Haematoxylin and eosin $\times 50$.

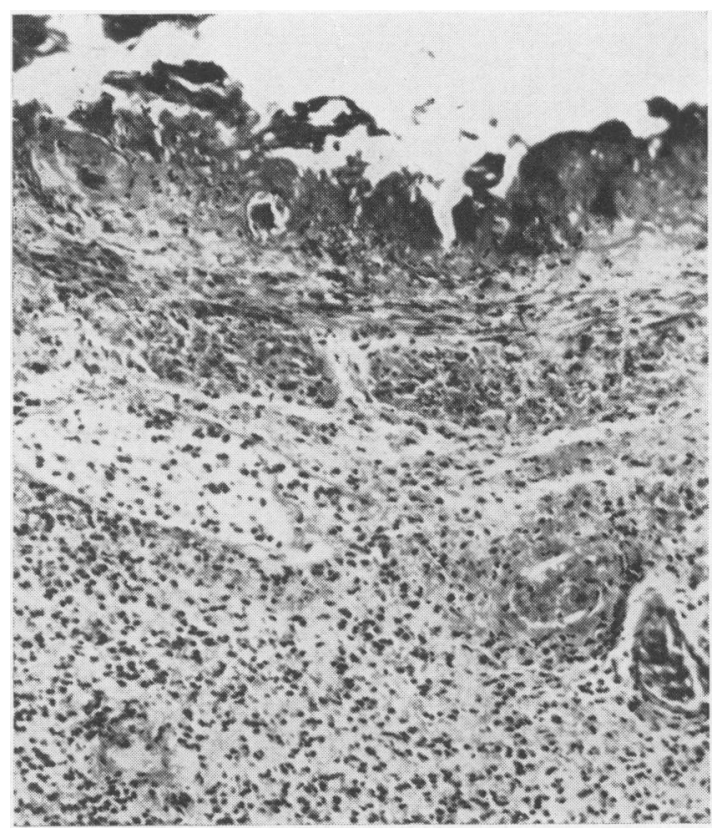

FIG. 8. The same as in Figure 7. Haematoxylin and eosin $\times 130$. 


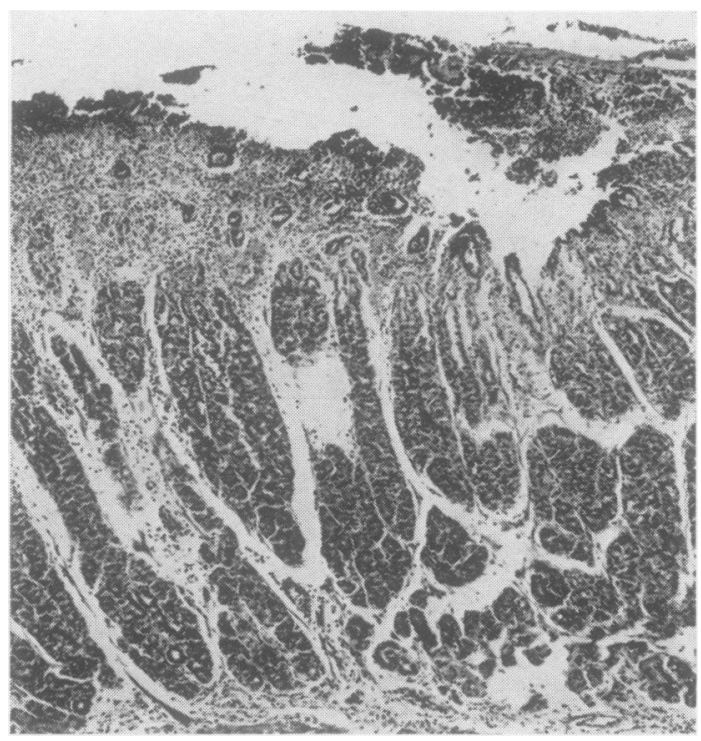

FIG. 9. Explanted gastric mucosa 48 hours after removal of aspirin. The biopsy was taken from the same explant as in Figs. 7 and 8 from a site adjacent to the area which had been covered by aspirin. Haematoxylin and eosin $\times 50$.

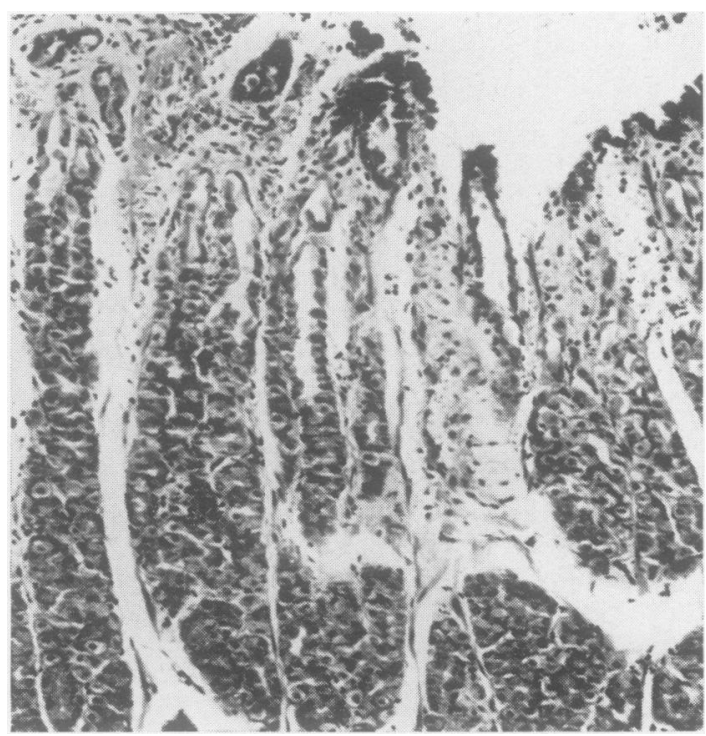

FIG. 10. The same as in Figure 9. Haematoxylin and $\operatorname{eosin} \times 130$.
DISCUSSION

From the many experiments and clinical observations much is known of the effect of both oral and parenteral salicylates on gastric mucosa (Douthwaite and Lintott, 1938; Grossman, Matsumoto, and Lichter, 1961; Roth, Valdes-Dapena, Pieses, and Buchman, 1963). The macroscopic and microscopic changes have been clearly documented and some evidence has been given that nausea due to salicylates is at least partly of central origin (Caravati and Cosgrove, 1946). There still remains, however, considerable doubt concerning the effects of salicylates on gastric secretory function. Some workers have reported that aspirin increases gastric acidity (Schnedorf, Bradley, and Ivy, 1936; Davison, Smith, and Smith, 1962), whereas others have reported a reduced acid output (Winkelman and Summerskill, 1961) and that gastric bleeding occurred while the acidity was very low (Lynch, Shaw, and Milton, 1964).

From the present experiments it may be concluded that the superficial erosions and inflammation of the gastric mucosa are not a result of increased acidity. The local application of aspirin was immediately followed by failure to detect acid on that area, even though in the early stages the inflammation and erosions were quite superficial and the deeper gastric glands histologically appeared to be unaffected. In these experiments the inflammation and depression of acid secretion spread to the adjacent areas of mucous membrane except when the animal was repeatedly stimulated with histamine. Repeated stimulation appeared to protect the adjacent mucous membrane as indicated by the retention of its capacity to secrete acid and the normal histological appearance. This protection may have been due to the continuous secretion of gastric juice washing away all traces of aspirin.

Previous work in these laboratories has shown that systemic absorption of large amounts of aspirin in cats inhibits the flow of gastric juice (Lynch et al., 1964), but the results obtained in the present experiments are clearly not due to absorption of large amounts of aspirin as there was no detectable loss of aspirin from the mucosal surface.

\section{SUMMARY}

In 16 dogs a section of the gastric wall with intact blood supply was explanted onto the abdominal wall. Direct application of powdered aspirin caused an inhibition of acid secretion in response to histamine even though at this stage the gastric glands appeared histologically to be unaffected. This inhibition of acid secretion was rapidly followed by 
the histological appearance of a severe superficial inflammation which initially resulted in loss of surface epithelium and eventually destroyed the full depth of mucous membrane. Both the inability to secrete acid and the inflammation spread to adjacent gastric mucosa except when repeated injections of histamine were given. The findings indicate that acute aspirin gastritis is not the result of increased acid secretion.

We were fortunate in having the advice and help of many friends in conducting these experiments. We wish particularly to thank Dr. Annette Lynch, Mr. Garth Maxwell, Mr. John Rochfort, Mr. Ken Clifford, and Mr. Robert Taylor.

\section{REFERENCES}

Caravati, C. M., and Cosgrove, E. F. (1946). Salicylate toxicity: the probable mechanism of its action. Ann. intern. Med., 24, 638642.
Davison, C., Smith, B. W., and Smith, P. K. (1962). Effects of buffered and unbuffered acetylsalicylic acid upon the gastric activity of normal human subjects. J. pharm. Sci., 51, 759-763.

Douthwaite, A. H., and Lintott, G. A. M. (1938). Gastroscopic observation of the effect of aspirin and certain other substances on the stomach. Lancet, 2, 1222-1225.

Grossman, M. I., Matsumoto, K. K., and Lichter, R. J. (1961). Fecal blood loss produced by oral and intravenous administration of various salicylates. Gastroenterology, 40, 383-388.

Lynch, A., Shaw, H., and Milton, G. W. (1964). Effect of aspirin on gastric secretion. Gut, 5, 230-236.

Milton, G. W., and Finckh, E. S. (1960). Dedifferentiation and loss of acid secretion in exteriorized gastric mucosa. Gastroenterology, 39, 312-318.

Roth, J. L. A., Valdes-Dapena, A., Pieses, P., and Buchman, E. (1963) Topical action of salicylates in gastrointestinal erosion and hemorrhage. Ibid., 44, 146-158.

Schnedorf, J. G., Bradley, W. B., and Ivy, A. C. (1936). Effect of acetylsalicylic acid upon gastric activity and the modifying action of calcium gluconate and sodium bicarbonate. Amer $J$. dig. Dis., 3, 239-244.

Winkelman, E. I., and Summerskill, W. H. J. (1961). Gastric secretion in relation to gastrointestinal bleeding from salicylate compounds. Gastroenterology, 40, 56-63.

Wood, P. H. (1963). Salicylates. Bull. rheum. Dis., 13, 297-300. 